\title{
¿Why Has the Inner Tibetan Plateau Become Wetter since the Mid-1990s?
}

\author{
JING SUN \\ Ministry of Education Key Laboratory for Earth System Modeling, Department of Earth System Science, Tsinghua \\ University, Beijing, China \\ KUN YANG \\ Ministry of Education Key Laboratory for Earth System Modeling, Department of Earth System Science, Tsinghua \\ University, and Center for Excellence in Tibetan Plateau Earth Science and National Tibetan Plateau Data Center, Institute of \\ Tibetan Plateau Research, Chinese Academy of Sciences, Beijing, China

\section{WEIDONG GUO} \\ Institute for Climate and Global Change Research, School of Atmospheric Sciences, and Joint International Research \\ Laboratory of Atmospheric and Earth System Sciences, Nanjing University, Nanjing, China \\ YAN WANG, JiE HE, AND Hui LU \\ Ministry of Education Key Laboratory for Earth System Modeling, Department of Earth System Science, Tsinghua \\ University, Beijing, China
}

(Manuscript received 27 June 2019, in final form 8 July 2020)

\begin{abstract}
The Inner Tibetan Plateau (ITP; also called the Qiangtang Plateau) appears to have experienced an overall wetting in summer (June, July, and August) since the mid-1990s, which has caused the rapid expansion of thousands of lakes. In this study, changes in atmospheric circulations associated with the wetting process are analyzed for 1979-2018. These analyses show that the wetting is associated with simultaneously weakened westerlies over the Tibetan Plateau (TP). The latter is further significantly correlated with the Atlantic multidecadal oscillation (AMO) on interdecadal time scales. The AMO has been in a positive phase (warm anomaly of the North Atlantic Ocean sea surface) since the mid-1990s, which has led to both a northward shift and weakening of the subtropical westerly jet stream at $200 \mathrm{hPa}$ near the TP through a wave train of cyclonic and anticyclonic anomalies over Eurasia. These anomalies are characterized by an anomalous anticyclone to the east of the ITP and an anomalous cyclone to the west of the ITP. The former weakens the westerly winds, trapping water vapor over the ITP while the latter facilitates water vapor intruding from the Arabian Sea into the ITP. Accordingly, summer precipitation over the ITP has increased since the mid-1990s.
\end{abstract}

KEYWORDS: Teleconnections; Jets; Precipitation; Summer/warm season; Wind

\section{Introduction}

The Tibetan Plateau (TP) is known as the "Roof of the World" or the "Third Pole" of Earth, with an average altitude of more than $4000 \mathrm{~m}$ above mean sea level (Qiu 2008). Because of its prominent and complex

¿ Denotes content that is immediately available upon publication as open access.

Corresponding author: Dr. Prof. Kun Yang, yangk@tsinghua. edu.cn topography, the TP is very sensitive to global climate changes. In addition, the plateau is also known as the "Asian Water Tower" because it is the source region for most of Asia's major rivers, providing water for billions of people (Xu et al. 2008; Immerzeel et al. 2010; Yao et al. 2012; Curio and Scherer 2016). Therefore, the water cycle in the TP, especially changes in precipitation, has been a topic of wide concern.

Meteorological stations are relatively densely distributed in the central and eastern TP, whereas there are very few stations in the western TP due to its harsh natural conditions; this seriously hinders the understanding of 
precipitation variability in the western TP (Shen and Xiong 2016). At the same time, there is an urgent need to understand climate changes in this region because of drastic lake expansion in the Inner TP (ITP; also called the Qiangtang Plateau) since the mid-1990s (Lei et al. 2013, 2014; Yang et al. 2018; Qiao et al. 2019; Zhang et al. 2019a). The ITP consists of the main part of the western TP and a part of the central TP and holds about 820 lakes larger than $1 \mathrm{~km}^{2}$ (Zhang et al. 2019b). This lake expansion has been related to the increase in precipitation during the past two decades according to station data (Yang et al. 2011, 2014; Lei et al. 2014), gridded data (Yao et al. 2012; Qiao et al. 2019), and observations of an increase in terrestrial water storage (Zhang et al. 2017a,b). Nevertheless, it is not clear how these local climate changes are related to changes in atmospheric circulations.

Previous studies have shown that the eastern and western TP exhibit different climatic characteristics (Ueda et al. 2003). Meanwhile, climate projections suggest that the western TP will become wetter under future global warming. Kitoh and Arakawa (2016) projected climate changes in the TP under the RCP8.5 scenario and suggested that the present east-west contrast in water budget across the TP climatologically could decrease in the future warming climate of 207599: specifically, precipitation, soil moisture, and runoff in the western TP may all increase at rates greater than those in the eastern TP. Several CMIP5 GCMs have produced projections of increased precipitation for the years 2015-35, possibly resulting in the continuous expansion of lakes in the ITP (Yang et al. 2018), yet atmospheric circulations relevant to the wetting process have not been investigated.

Recently, Zhou et al. (2019) studied the TP as a whole to explain the wetting, but the precipitation changes show large spatial variability (more wetting in the western and central TP and less wetting in the eastern TP), as concluded from many studies (Yang et al. 2011; Bibi et al. 2018). For instance, Yang et al. (2014) pointed out that annual precipitation had decreased in the southern and eastern TP, but increased in the central TP since the 1980s. Also, a time series of precipitation constructed by Liu et al. (2018) using a new interpolation method showed that annual precipitation over the southeastern TP decreased significantly after 1998, whereas that over the northeastern part had increased slightly since 2002. Given the great spatial heterogeneity of precipitation changes in the TP, this study specifically focuses on the wetting in the ITP, where the wetting is most pronounced and thousands of lakes have been expanding since the mid1990s. Our intention was to provide a comprehensive understanding of the ITP precipitation variability under the influence of global climate changes. We investigated interdecadal variations of summer [June-August (JJA)] precipitation over the ITP and its associated atmospheric circulations and water vapor transport for the years 19792018. The rest of this paper is arranged as follows. Section 2 describes the study domain, data, and methods. Section 3 examines interdecadal variations of the summer precipitation over the ITP and associated atmospheric anomalies, and then further investigates the effect of the Atlantic multidecadal oscillation (AMO) on precipitation. Section 4 discusses the processes of those linkages, and section 5 presents the summary of this study.

\section{Study domain, data, and method}

The ITP is the study domain of this study, which is shown in Fig. 1a. According to station data, approximately $70 \%$ of the total annual precipitation over the ITP falls in summer (Figs. 1b-k). Although precipitation in September is comparable to that in June, we found that the interdecadal change of precipitation in September was opposite to that in summer. Therefore, we did not take September into consideration and selected summer (JJA) for analysis.

\section{a. Data}

\section{1) IN SITU DATA}

Monthly precipitation observations at stations were obtained from the China Meteorological Administration (CMA) for the years 1979-2018. There are 14 available meteorological stations located in or near the ITP, but five of these are located at the southwestern edge of the TP, where lakes have been shrinking since 1976 (Lei et al. 2014), indicating that its climate changes are different from those in the ITP, so these five stations were not used in this study. The locations of the remaining nine stations are shown in Fig. 1a. All the stations have elevations higher than $4000 \mathrm{~m}$ above mean sea level and are located in relatively flat areas, except for Bange station, which is at the foot of a mountain.

\section{2) GRIDDED DATA}

Given that sparse in situ data cannot be used to determine spatial patterns of precipitation change in the ITP, we adopted the following gridded datasets. The European Centre for Medium-Range Weather Forecasts (ECMWF) interim reanalysis (ERA-Interim) data for 1979-2018 were used, including monthly precipitation, wind, specific humidity, water vapor flux, and geopotential height. In this study, we used $0.75^{\circ} \times 0.75^{\circ}$ gridded precipitation data and $0.125^{\circ} \times 0.125^{\circ}$ gridded data for other variables (Berrisford et al. 2011; Dee et al. 2011). As well 


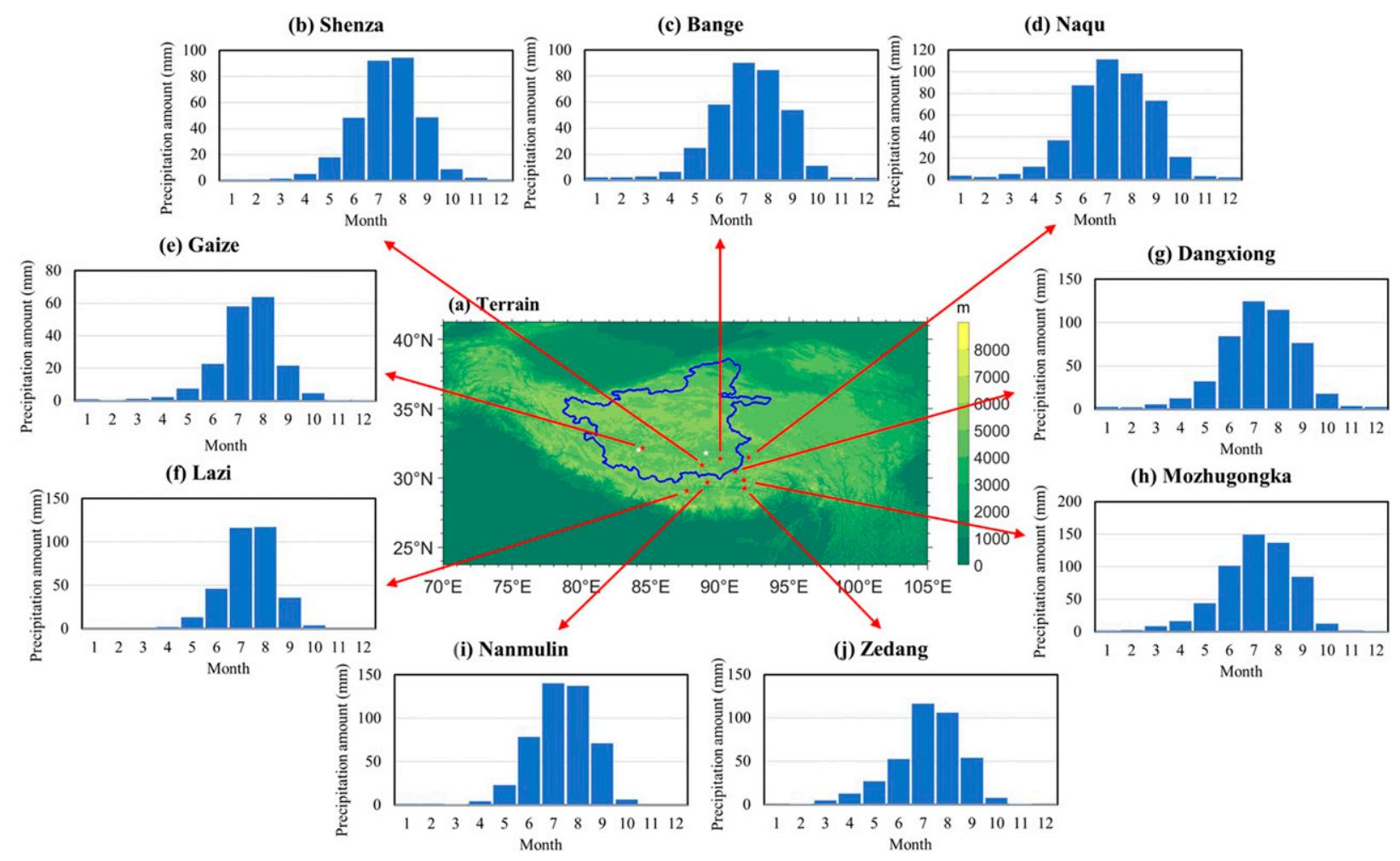

FIG. 1. (a) The terrain (shaded) of the TP and the location of the ITP (the blue polygon). Red stars denote locations of meteorological stations in or near the ITP. The left white star denotes the location of Lagkor Co, and the right white star is Siling Co. (b)-(j) Monthly precipitation amount averaged over the years 1979-2018 at each station. The data of the ITP basin are from the dataset of the river basins map over the TP (2016) (Zhang et al. 2013; Zhang 2019).

as precipitation changes, the ERA-Interim data were used to analyze the meridional position and strength of the subtropical westerly jet stream, and the distributions of water vapor flux and other factors. To test the robustness of results for a longer period, we also used the monthly NCEP-NCAR (1948-2018; Kalnay et al. 1996) and JRA55 (1958-2013; Kobayashi et al. 2015) reanalysis data with spatial resolutions of $2.5^{\circ}$ and $1.25^{\circ}$, respectively. For the monthly sea surface temperature (SST), we used the Hadley Centre Sea Ice and Sea Surface Temperature dataset (HadISST), which has a spatial resolution of $1^{\circ}$ (Rayner et al. 2003).

To further confirm the results derived from the observed and ERA-Interim precipitation data, two other precipitation products were used. One is the monthly precipitation data from the China Meteorological Forced Dataset (CMFD), which has a spatial resolution of $0.1^{\circ}$ and covers 1979-2018. This dataset is a fusion product that is based on satellite precipitation data and in situ data from 740 CMA stations (He and Yang 2011; He et al. 2020). The other is the standard monthly precipitation data from the CPC Merged Analysis of Precipitation (CMAP), which has a spatial resolution of $2.5^{\circ}$ and covers $1979-2018$. It was produced using five kinds of satellite estimates and gauge data (Xie and Arkin 1997).

\section{3) AMO INDEX}

The AMO is a kind of natural variability consisting of multidecadal changes in SST in the North Atlantic Ocean at a basin scale (Kerr 2000). The monthly AMO index is obtained by computing the area-weighted average over the North Atlantic Ocean (basically $0^{\circ}-$ $70^{\circ} \mathrm{N}$ ), using the Kaplan SST dataset (Enfield et al. 2001). We used the unsmoothed data without detrending for the years 1979-2018. Interdecadal variations were extracted from these data for our analysis. We also used the unsmoothed but detrended AMO index to repeat all the analyses and found that the results (not shown) were broadly similar.

\section{b. Method}

We used the following statistical methods to detect the relationships between precipitation and climate factors. First, cumulative anomalies were calculated to identify the interdecadal transition. The formula is as follows: 


$$
\hat{x}_{t}=\sum_{i=1}^{t}\left(x_{i}-\bar{x}\right), \quad(t=1,2, \ldots, n),
$$

where $x_{i}(i=1,2, \ldots, n)$ is the original time series, $\bar{x}$ is the sample mean during the period, $n$ is the sample size, and $\hat{x}_{t}(t=1,2, \ldots, n)$ is the cumulative anomaly at time $t$. The major turning points of cumulative anomalies can clearly capture interdecadal changes.

Second, 9-yr running means were used to analyze interdecadal variations of all the time series. All the standardized time series were obtained by zero-mean normalization. Third, composite analysis was employed to highlight circulation and water vapor anomalies associated with precipitation. In addition, we calculated correlation coefficients to quantitatively investigate the relationships among precipitation and climatic factors, such as the subtropical westerly jet stream and AMO.

Significance testing was performed using Student's $t$ test and the Monte Carlo method for differences and correlation coefficients on interdecadal time scales, respectively. In the $t$ test, the effective sample size $n_{e}$ that determines the degrees of freedom was estimated as follows (Zwiers and von Storch 1995):

$$
n_{e}=n /\left[1+2 \sum_{\tau=1}^{n-1}\left(1-\frac{\tau}{n}\right) \rho(\tau)\right] \approx \frac{n\left(1-r_{1}\right)}{1+r_{1}}
$$

where $n$ is the sample size, $\rho(\tau)$ is the autocorrelation between the variable at time $t$ and time $t+\tau$, and $r_{1}$ is the lag-1 correlation coefficient.

As for the Monte Carlo method for tests of correlation coefficients on interdecadal time scales, one of the two original time series was randomly rearranged to be a new time series. Then we calculated the correlation coefficient between the new time series and the other original time series. This process was repeated 5000 times, and a distribution of correlation values was finally obtained. The 5000 correlation coefficients were sorted from smallest to largest. When the value being tested is outside the $99 \%$ or $95 \%$ range of the sorted correlation coefficients, it is respectively considered to be significant at the 0.01 or 0.05 level.

\section{Results}

\section{a. Regionalization of interdecadal change in precipitation}

Many studies (Qiao et al. 2019; Zhang et al. 2019a) have shown that lake areas in the ITP have expanded greatly since the mid-1990s, and this expansion is mainly attributed to changes in precipitation (Lei et al. 2014; Yang et al. 2018). As shown in Fig. 2a, cumulative anomalies of summer precipitation at the nine stations (except for Bange station) in or near the ITP show a decreasing trend before around 1997 but an increasing trend afterward. This indicates that there are opposite precipitation anomalies between the two periods; that is, there is an obvious interdecadal transition of summer precipitation around 1997. The transitional year at Bange station is around 2003, relatively later than that at other stations (around 1997). The locations of Shenza and Bange stations are close, but there are differences in the amplitude and transitional year between them, which proves that local factors (such as that Bange station is located at the foot of a mountain) may have influence on the interdecadal transition of precipitation. Lei et al. (2014) found that the lake area expansion rate generally had a good relationship with the increase of precipitation observed by meteorological stations. Figure $2 \mathrm{~b}$ shows the lake area changes of Lagkor Co (near Gaize station) and Siling Co (near Bange and Shenza stations). Lake Lagkor Co expanded slowly, which was consistent with a slow increase in cumulative precipitation anomaly at Gaize station, whereas Lake Siling Co expanded rapidly, corresponding to a rapid increase in cumulative anomaly at Shenza station. From the above aspects, it is reasonable to deduce that summer precipitation over the ITP has an interdecadal transition around 1997. Figures 2c-e show the patterns of the relative changes in summer precipitation after and before 1997, using the ERA-Interim, CMFD, and CMAP datasets. The relative change is defined as the difference between 19982018 and 1979-97 divided by the mean of the whole period. Results from all the three datasets indicate that summer precipitation over the ITP has significantly increased since 1997. We also calculated the relative changes of measured summer precipitation, which were always positive (ranging from $9.1 \%$ to $35.8 \%$ with an average of $18.1 \%$ ) at the nine stations. The values of relative changes at Gaize, Shenza, and Bange stations are $35.8 \%, 23.9 \%$, and $9.9 \%$, respectively. These positive changes explicitly agree with the ERA-Interim, CMFD, and CMAP results.

In addition, Lin et al. (2013) showed that wind speeds over the TP had interdecadal changes, and a weaker wind speed after 1990s could be observed. Here, we examined the relationship between summer wind speed and precipitation over the TP. Figure 3 a shows the correlation coefficients between the ERA-Interim precipitation and zonal wind data on interdecadal time scales. We found that the TP $\left(25^{\circ}-40^{\circ} \mathrm{N}, 69^{\circ}-105^{\circ} \mathrm{E}\right)$ area-averaged zonal wind speed at $500 \mathrm{hPa}$ was significantly and negatively correlated with precipitation over the ITP in summer on interdecadal time scales. Considering both the lake expansion and climate characteristics, we selected the ITP region with the most significant correlation 

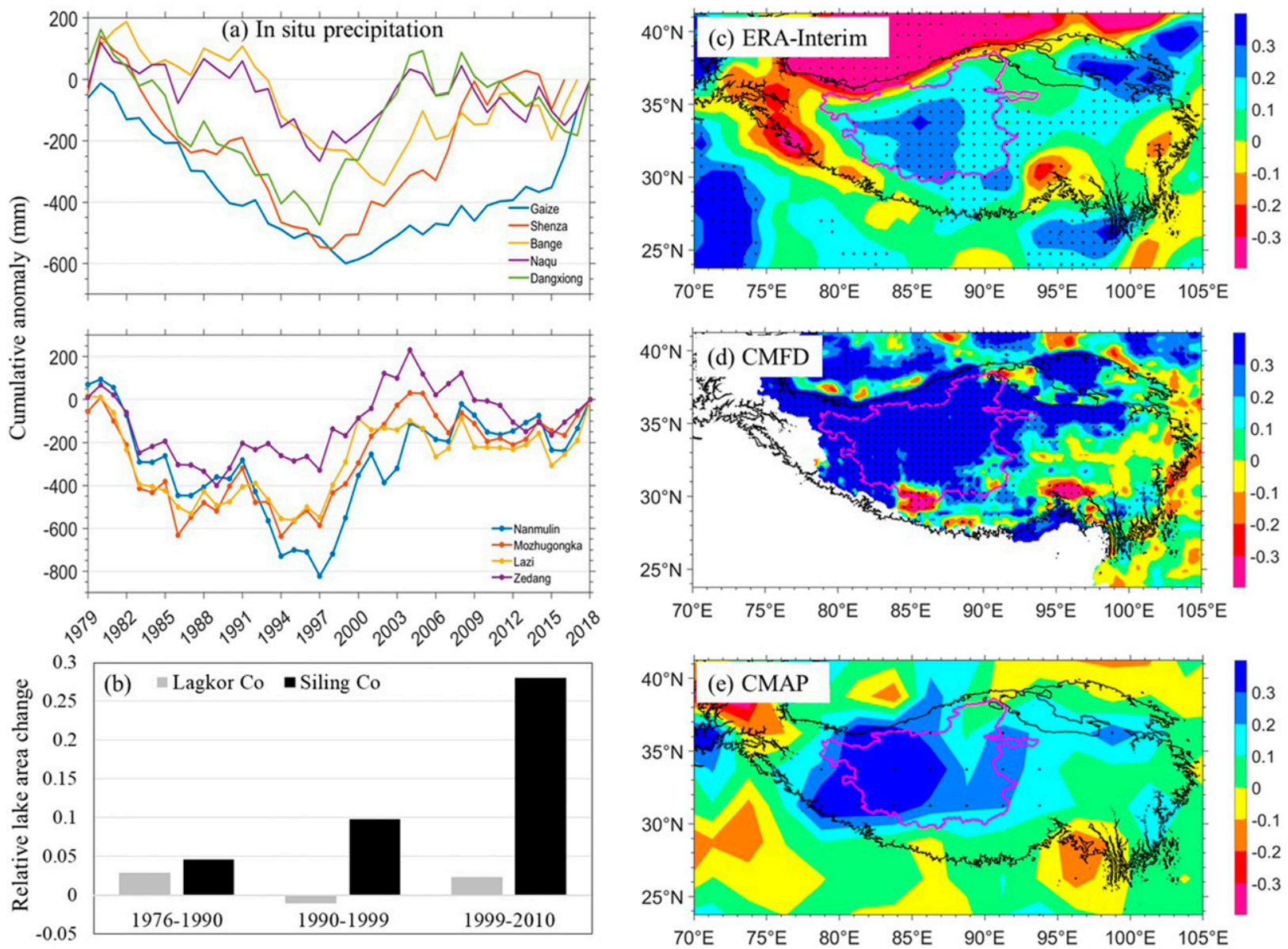

FIG. 2. (a) Cumulative anomalies of summer precipitation at the nine stations during 1979-2018. (b) Relative lake area changes of Lagkor Co (near Gaize station) and Siling Co (near Shenza and Bange stations). The lake data are provided by Dr. Y. Lei. Also shown are relative changes of summer precipitation after and before 1997 using the (c) ERA-Interim, (d) CMFD, and (e) CMAP datasets. The relative change is defined as the difference of 1998-2018 minus 1979-97 divided by the mean of the whole period. The dotted areas indicate relative changes that are significant at the 0.05 level. The magenta polygon denotes the location of the ITP. The black line denotes the 3000-m contour line of the TP.

coefficients (enclosed by the red solid line in Fig. 3a) for further analysis. This region is roughly west of $92^{\circ} \mathrm{E}$ and east of $80^{\circ} \mathrm{E}$, but it does not cover the Himalaya (where lakes have shrunk). Figure $3 \mathrm{~b}$ shows that the correlation coefficient between summer ITP-averaged precipitation and TP-averaged 500-hPa zonal wind speed exceeds -0.90 (significant at the 0.01 level). From the cumulative anomaly curves of the ITP precipitation and TP zonal wind speed during 1979-2018, we can clearly see that interdecadal transitions in both time series occurred around 1997 (Fig. 3c). Therefore, summer precipitation over the ITP is strongly and negatively correlated with the TPaveraged zonal wind speed on interdecadal time scales.

\section{b. Dependence of precipitation variability on atmospheric circulations}

To understand the negative correlation between summer ITP precipitation and TP-averaged zonal wind speed on interdecadal time scales, atmospheric circulation anomalies associated with variations of the ITP-averaged precipitation were analyzed. The ITP has become wetter since about 1997 (Fig. 3c), consistent with the observed expansion of lakes (Yang et al. 2018). The filtering method may have weakly influenced the transition year shown in Fig. 3b, but without substantially changing our results. Therefore, considering the observed lake expansion and results in Figs. $3 b$ and 3c, we defined the dry period of the ITP as 1979-97 and the wet period as 1998-2018.

Based on the above analysis of the interdecadal ITPaveraged precipitation, the corresponding circulation characteristics were analyzed to reveal the underlying mechanism responsible for the observed changes. Figure 4 shows differences in atmospheric circulations and moisture between the wet (1998-2018) and dry (1979-97) periods (the former minus the latter). In the positive phase (i.e., wet period), east wind anomalies at $500 \mathrm{hPa}$ appear over 
(a) Correlation between gridded precipitation and TP-averaged zonal wind

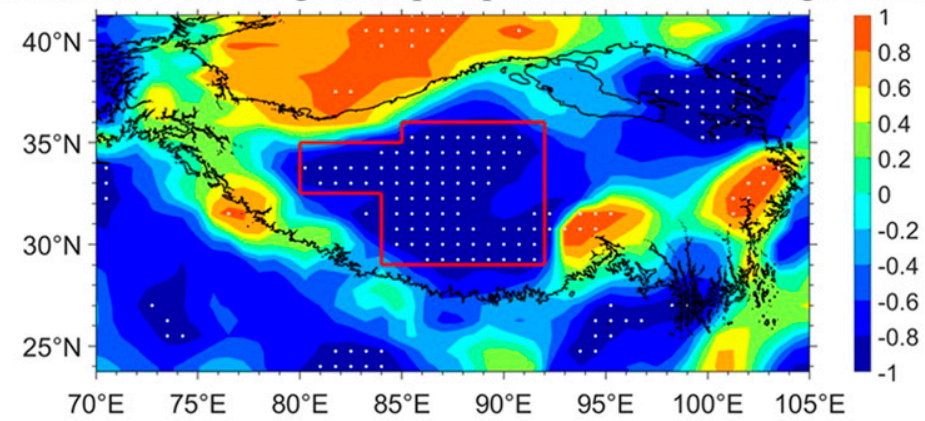

(b) Precipitation vs Zonal wind

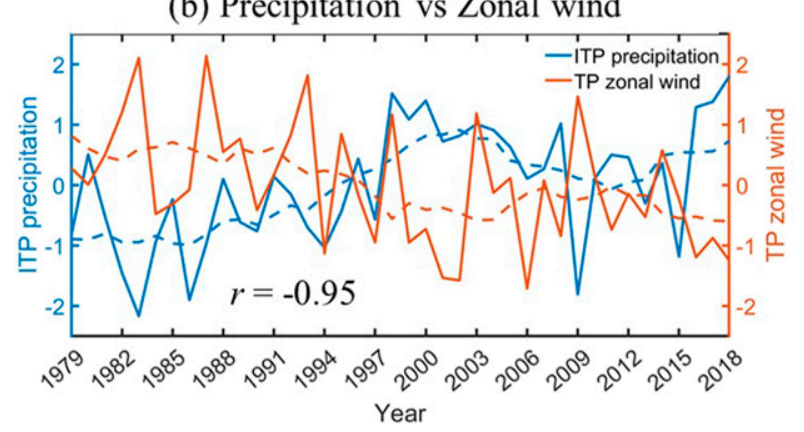

(c) Cumulative anomaly

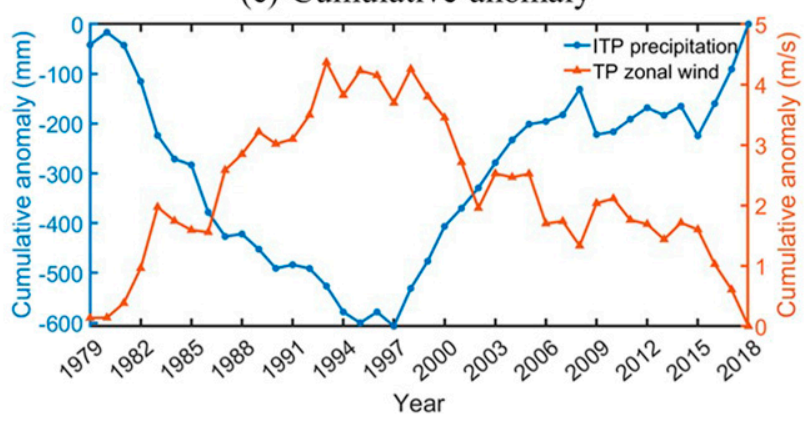

FIG. 3. (a) Correlation between the ERA-Interim gridded precipitation and TP-averaged 500-hPa zonal wind speed in summer on interdecadal time scales during 1979-2018. The dotted areas indicate correlation coefficients that are significant at the 0.01 level. The area enclosed by the red solid line is used in this study. The black line denotes the 3000-m contour line of the TP. (b) Time series of the standardized ITP-averaged precipitation and TP-averaged 500-hPa zonal wind speed in summer. The dashed lines indicate the corresponding interdecadal variations, obtained by a 9-yr running mean; $r$ is the correlation coefficient between the two interdecadal series. (c) Cumulative anomalies of the ITP precipitation and TP zonal wind in summer during 1979-2018.

the TP; that is, the westerlies weaken there, accompanied by increased specific humidity (Fig. 4a). More specifically, the east wind anomalies are particularly significant to the east of the ITP, as addressed in Zhou et al. (2019). But to the west of the ITP, there are small wind anomalies. This significant contrast between wind anomalies to the east and west of the ITP is beneficial to air convergence over the ITP. In this situation, water vapor carried by the westerlies is restrained over the ITP due to the anomalous easterlies, resulting in enhanced convergence of water vapor flux (Fig. 4b) over the ITP. This water vapor flux anomaly is essentially consistent with the results of Zhou et al. (2019), which showed that water vapor flux at the eastern boundary of the TP was reduced after 1994.

In addition to the westerlies, water vapor supply to the TP in summer can also be conveyed by the southwest monsoon flow (Z. Q. Wang et al. 2017). Figure 4b shows that water vapor transported from the Arabian Sea significantly increases at the southern boundary of the ITP, which is due to the enhanced southwest winds in the lower troposphere (not shown) and consistent with the enhanced southwest winds over the Arabian Sea and Indian subcontinent at $500 \mathrm{hPa}$ (Fig. 4a); meanwhile, the water vapor transported by the westerlies at the western boundary of the ITP shows no significant change. At the same time, as shown in Fig. 4c, the vertical velocity $\omega$ presents significant overall negative anomalies centered at $22^{\circ}$ and $28^{\circ} \mathrm{N}$ over the Indian subcontinent, indicating enhanced ascending motion and convection. The enhanced convection over the Indian subcontinent is attributed to the trough anomaly to the west of the ITP. These vertical velocity anomalies can extend to $500 \mathrm{hPa}$ or even higher. In other words, water vapor from the Arabian Sea can be lifted to the midtroposphere by enhanced convection over the Indian subcontinent. The midtropospheric water vapor is then advected into the ITP boundary layer by enhanced southwest winds, which favors more precipitation over the ITP. This "up-and-over" transport process was proposed by Dong et al. (2016).

The subtropical westerly jet stream over the Northern Hemisphere is a planetary-scale atmospheric circulation system in the upper troposphere, and its anomalies have important influence on the middle and lower atmospheric circulations (Yang et al. 2002; Lin and Lu 2005). Many studies have shown that the jet stream has significant influence on the climate of Asia, especially on 
(a) $500 \mathrm{hPa}$ wind and specific humidity

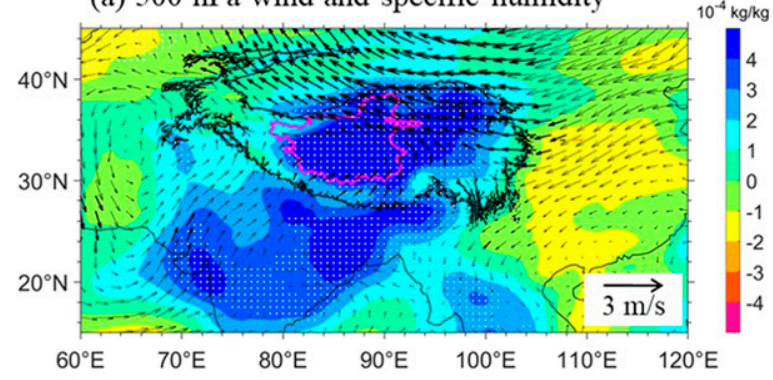

(c) Vertical velocity $(\omega)$

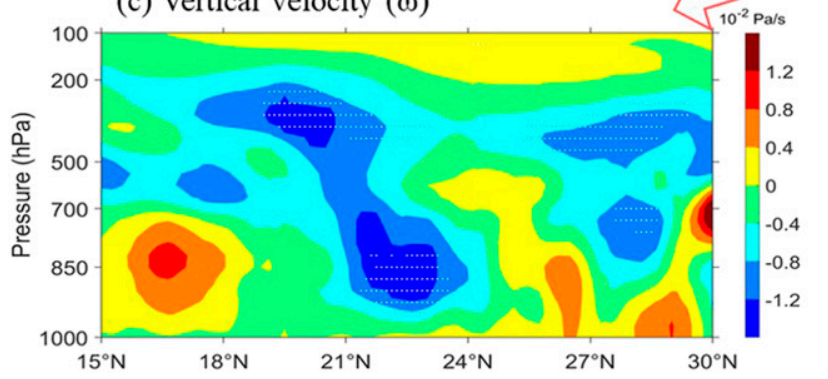

(b) Water vapor flux and its divergence

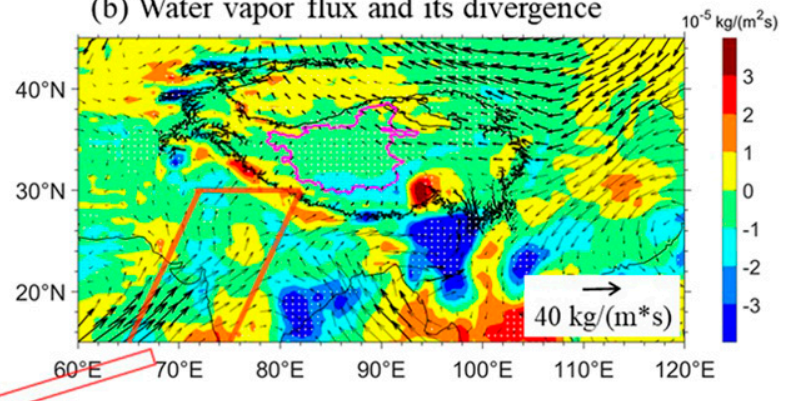

(d) $200 \mathrm{hPa}$ zonal wind

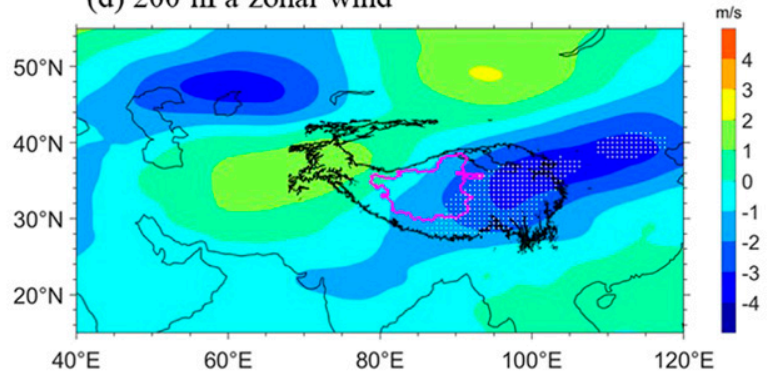

FIG. 4. (a) Differences in specific humidity (shaded) and wind (vectors), (b) vertical integral of water vapor flux (vectors) and its divergence (shaded), (c) vertical velocity $\omega$, and (d) zonal wind at $200 \mathrm{hPa}$ in summer between the wet (1998-2018) and dry (1979-97) periods (the former minus the latter). Vertical velocity differences of the latitude-vertical section are shown in (c), averaged over the region enclosed by the red solid line in (b). The dotted areas and thick arrows indicate differences that are significant at the 0.01 level. The magenta polygon denotes the location of the ITP. The black line denotes the 3000-m contour line of the TP.

precipitation (Liang and Wang 1998; Yang and Zhang 2008; Sampe and Xie 2010; Zhao et al. 2014; Xie et al. 2015). Zhao et al. (2018) found that 15 CMIP5 models could capture the influence of the subtropical westerly jet on summer precipitation over central Asia, which was observed in the NCEP-NCAR reanalysis data and CRU version 3.10 monthly precipitation data for the period 1961-2004. Ten of the models projected the persistence of this relationship into the future under the RCP8.5 scenario (2051-2100), indicating the robustness of the jet's influence on precipitation over central Asia. However, it remains unclear how the subtropical jet stream affects summer precipitation over the ITP. Here, we investigate the relationship between the jet stream and the ITP precipitation on interdecadal time scales. Figure $4 \mathrm{~d}$ shows differences in zonal wind at $200 \mathrm{hPa}$ during summer between the wet and dry periods. It can be seen that over the ITP and regions to its east, there are significant negative anomalies to the south of about $40^{\circ} \mathrm{N}$ and positive anomalies to its north, indicating that the subtropical jet stream near the TP is displaced to the north. By contrast, to the west of the ITP, the signs of these anomalies are exactly the opposite, corresponding to the southward shift of the jet stream over there. Thus, the jet stream has become more meandered, transporting more water vapor from the Arabian Sea to the plateau. The similar patterns of wind anomalies at 200 and $500 \mathrm{hPa}$ suggest that these anomalies exhibit a barotropic structure, indicating that these anomalies in the upper troposphere are part of an anomalous barotropic wave train. More discussion is given in section $4 \mathrm{~b}$.

To quantitatively analyze the relationship between the jet stream and precipitation, we defined two jet stream indices. Similar to the methods used by Kuang and Zhang (2006), the position index of the jet stream is defined as the average latitude of the maximum westerly wind at $200 \mathrm{hPa}$ at each longitude over the domain of $30^{\circ}-50^{\circ} \mathrm{N}$ and $80^{\circ}-120^{\circ} \mathrm{E}$, where the jet stream shows the strongest anomalies (Fig. 4d). In the same way, the strength index of the jet stream is defined as the mean of the maximum westerly wind speed at $200 \mathrm{hPa}$ at each longitude over the same domain.

Figures $5 \mathrm{a}$ and $5 \mathrm{~b}$ show the relationship between the summer jet stream indices and ITP-averaged precipitation on interdecadal time scales. The summer jet stream position is positively correlated with the ITP-averaged precipitation ( $r=0.69$; Fig. $5 \mathrm{a})$; that is, the summer precipitation increases when the jet stream moves northward. Meanwhile, the summer jet stream strength is significantly and negatively correlated with the precipitation with a correlation coefficient of -0.92 , indicating that interdecadal variations of summer jet stream strength and ITP-averaged precipitation are almost antiphase (Fig. 5b). 

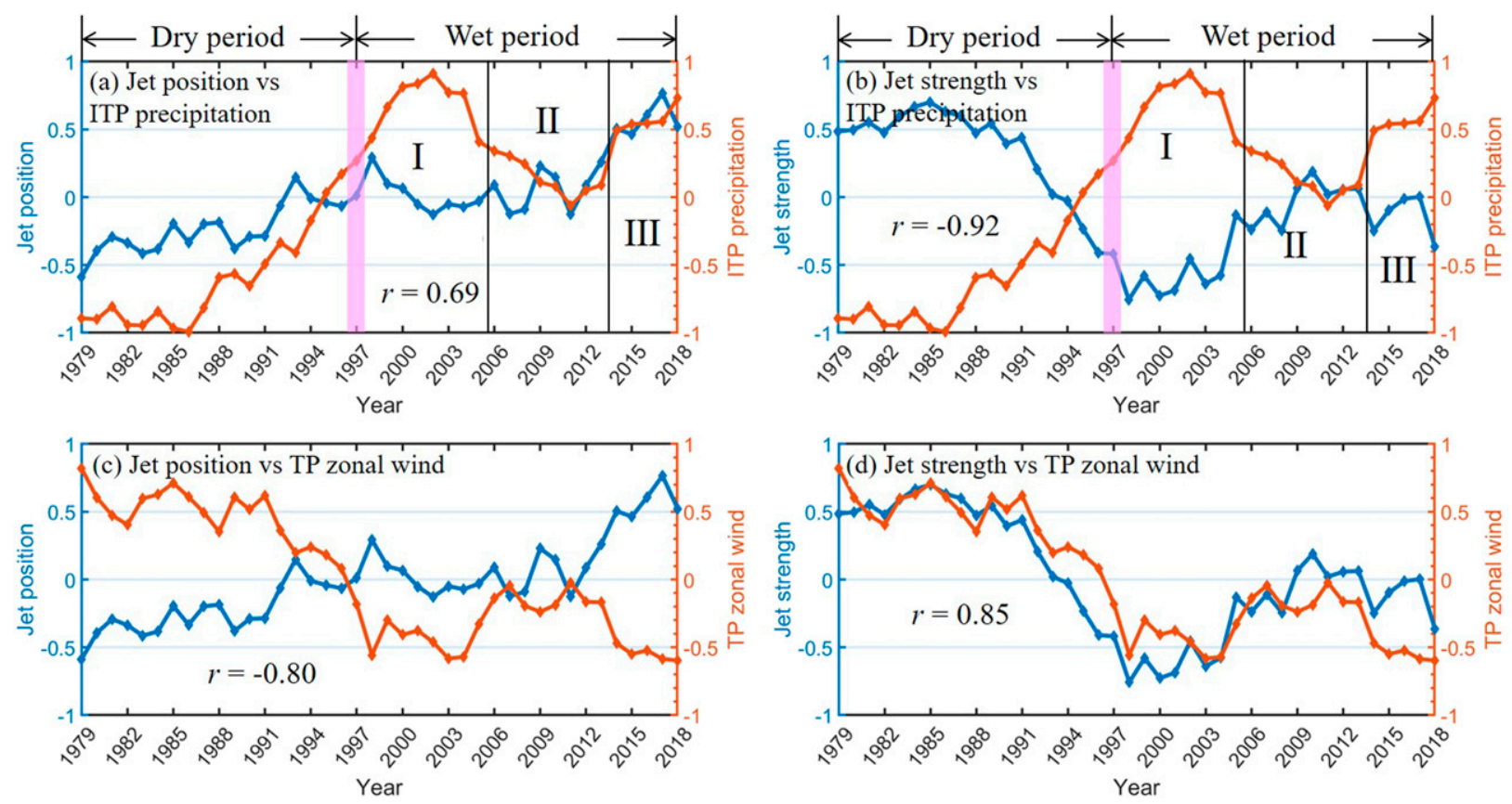

FIG. 5. (a),(b) Interdecadal variations of summer ITP-averaged precipitation and position [in (a)] and strength [in (b)] indices of the subtropical westerly jet stream. The thick magenta vertical line divides the years 1979-2018 into dry and wet periods. The two thin black vertical lines subdivide the wet period into three subperiods (wet periods I, II, and III). (c),(d) Interdecadal variations of summer TPaveraged zonal wind speed at $500 \mathrm{hPa}$ and jet stream position [in (c)] and strength [in (d)] indices. In all panels, $r$ is the correlation coefficient between the two series. All of the time series are standardized before extracting their interdecadal variations.

The wetting process in the ITP can be explained by both the position and strength of the jet stream. As shown in Figs. 5a and 5b, a southward shift and enhanced strength of the jet stream jointly caused the dry period of 1979-97 in the ITP. The wet period of 1998-2018 comprises three subperiods. The years 1998-2005 (wet period I) saw a heavy wetting of the ITP; during this period the jet stream was near its normal position, but its strength was very weak, which was conducive to the increase in summer precipitation over the ITP. Therefore, wet period I was mainly caused by the weakening of the jet stream. The years 2006-13 (wet period II) were normal in terms of the precipitation, corresponding to the normal strength and position of the jet stream during this period. The years 2014-18 (wet period III) represented another wetting period, except for the year 2015 which was dry (Fig. 3b) due to a very strong El Niño (Lei et al. 2019). During this period, the jet stream was shifting northward with normal strength, but it seems to have been weakening since 2017. Under the combined influence of these two factors, the ITP reentered a period of rapid wetting. These three distinct periods since 1997 correspond roughly to three stages of lake expansion: rapid before 2006, then slowing down, and then rapid again after 2013 (Zhang et al. 2019b). These results demonstrate that both the position and strength of the jet stream near the TP may have played important roles in summer precipitation changes over the ITP during the past four decades.

We also note that the correlation coefficient of the TPaveraged 500-hPa zonal wind speed with the jet stream position is as strong as -0.80 (Fig. $5 \mathrm{c}$ ), while that with the jet stream strength reaches 0.85 (Fig. 5d). Clearly, the TP zonal wind speed is also affected jointly by the position and strength of the jet stream.

In summary, the increased summer precipitation over the ITP on interdecadal time scales can be attributed to both the northward shift and decreased strength of the jet stream near the TP, which have jointly led to weakened westerly winds and enhanced air convergence over the TP. This meander of the jet stream is also conducive to water vapor transport from the Arabian Sea. These changes allow more water vapor to converge over the ITP, consequently increasing precipitation. Conversely, when the jet stream near the TP is anomalously southward or strong, the westerlies over the TP are strengthened, and water vapor convergence over the ITP becomes weaker, resulting in less precipitation.

\section{c. Teleconnection between the AMO and ITP summer precipitation}

Previous studies have demonstrated that the AMO influences Asian summer precipitation (Wang et al. 2009; 
(a) AMO vs Gridded precipitation
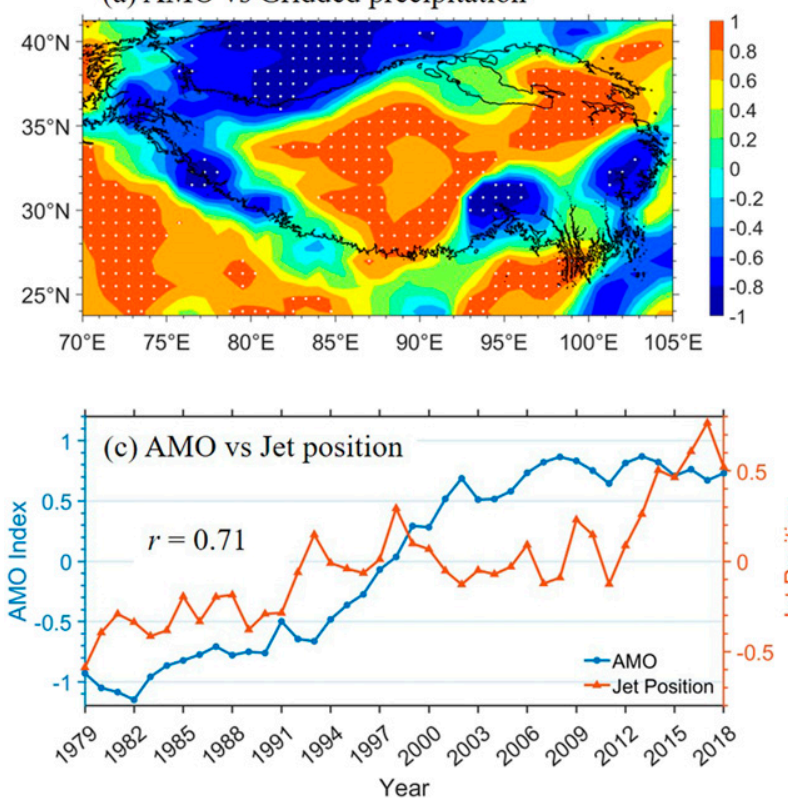
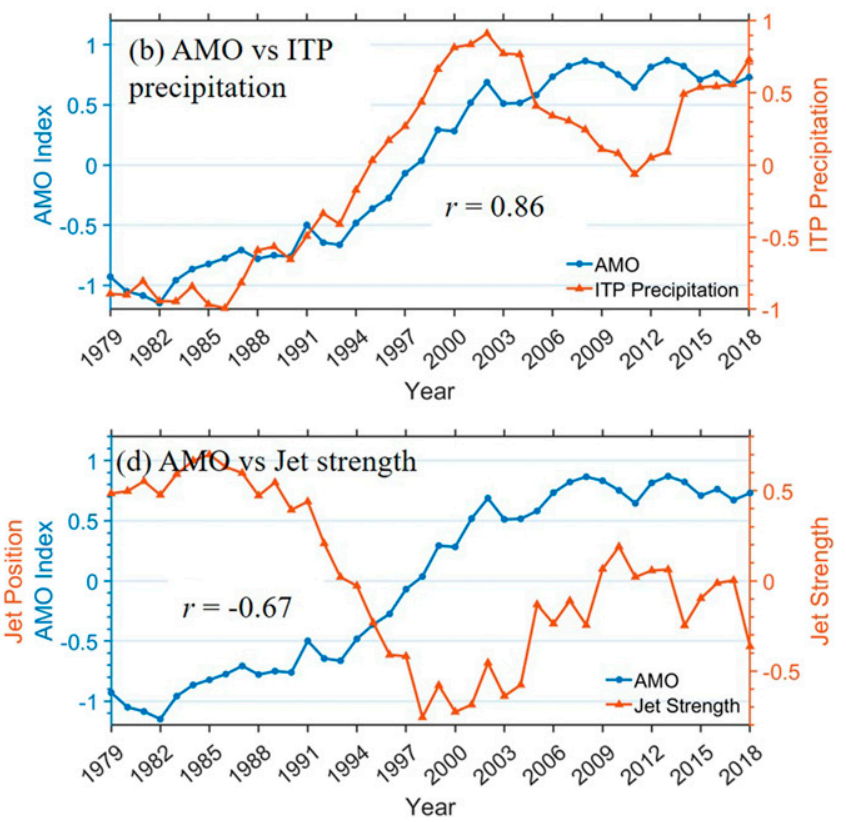

FIG. 6. (a) Correlation between summer gridded precipitation (ERA-Interim) and AMO index on interdecadal time scales during 19792018. The dotted areas indicate correlation coefficients that are significant at the 0.05 level. The black line denotes the $3000-\mathrm{m}$ contour line of the TP. Also shown are interdecadal variations of summer AMO index, (b) ITP-averaged precipitation, and (c) position and (d) strength indices of the subtropical westerly jet stream during 1979-2018; $r$ is the correlation coefficient between the two series. All of the time series are standardized before extracting their interdecadal variations.

Si and Ding 2016). Thus, the teleconnection relationship between the AMO and ITP summer precipitation deserves to be analyzed. The pattern of the correlation between gridded precipitation from the ERA-Interim dataset and AMO index in summer on interdecadal time scales shows that there are significantly positive correlations over the ITP (Fig. 6a). As shown in Fig. 6b, the correlation coefficient between the summer AMO index and ITP-averaged precipitation on interdecadal time scales was as high as 0.86 . This result indicates that there is more summer precipitation over the ITP during the warm phase of the AMO.

To further explore physical processes of how the AMO affects summer precipitation over the ITP, we first analyzed the relationship between the AMO and the subtropical westerly jet stream. As shown in Figs. $6 \mathrm{c}$ and $6 \mathrm{~d}$, the AMO is correlated with both summer jet stream position $(r=0.71)$ and strength $(r=-0.67)$. Therefore, it is reasonable to infer that the AMO can affect both the position and strength of the jet stream, resulting in summer precipitation changes over the ITP.

Above all, on interdecadal time scales, the AMO is a key factor affecting summer precipitation changes over the ITP. A positive AMO index, featuring positive sea surface temperature anomalies in the North Atlantic, leads to both the northward shift and weakened strength of the jet stream near the TP. In contrast, during the negative phase of the AMO, these anomalies reverse.

\section{Discussion}

\section{a. Sensitivity of results to selected precipitation data}

To examine the robustness of these results and show that they are not affected by different precipitation data sources, the CMFD and CMAP precipitation data were used to replace the ERA-Interim precipitation data in the analysis.

As shown in Figs. 7a and 7b, a similar relationship between TP-averaged zonal wind and gridded precipitation over the ITP also can be seen with the CMFD and CMAP datasets. In addition, the interdecadal transition around 1997 is also identified in both cases (Fig. 7c). These results confirm the reliability of the ERA-Interim data in reflecting interdecadal variations of precipitation and the relationship of the precipitation and TP zonal wind in summer over the ITP. Figures $8 \mathrm{a}$ and $8 \mathrm{~b}$ show the spatial patterns of correlation coefficients between the summer AMO and precipitation, using the CMFD and CMAP datasets. Again, the results using different precipitation datasets yield similar patterns in the ITP, which reconfirms that the ITP precipitation is strongly correlated with the AMO on interdecadal time scales 


\section{(a) CMFD gridded precipitation vs TP-averaged zonal wind}

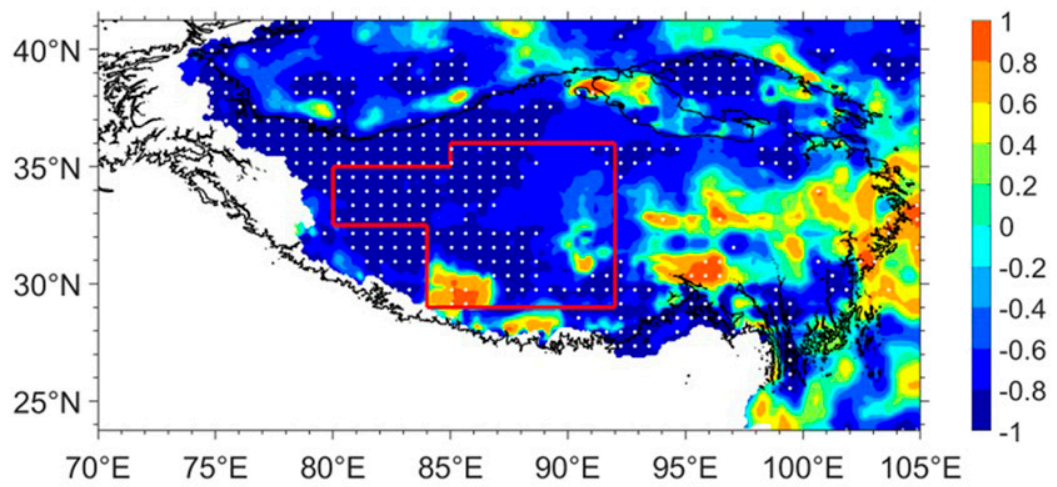

(b) CMAP gridded precipitation vs TP-averaged zonal wind
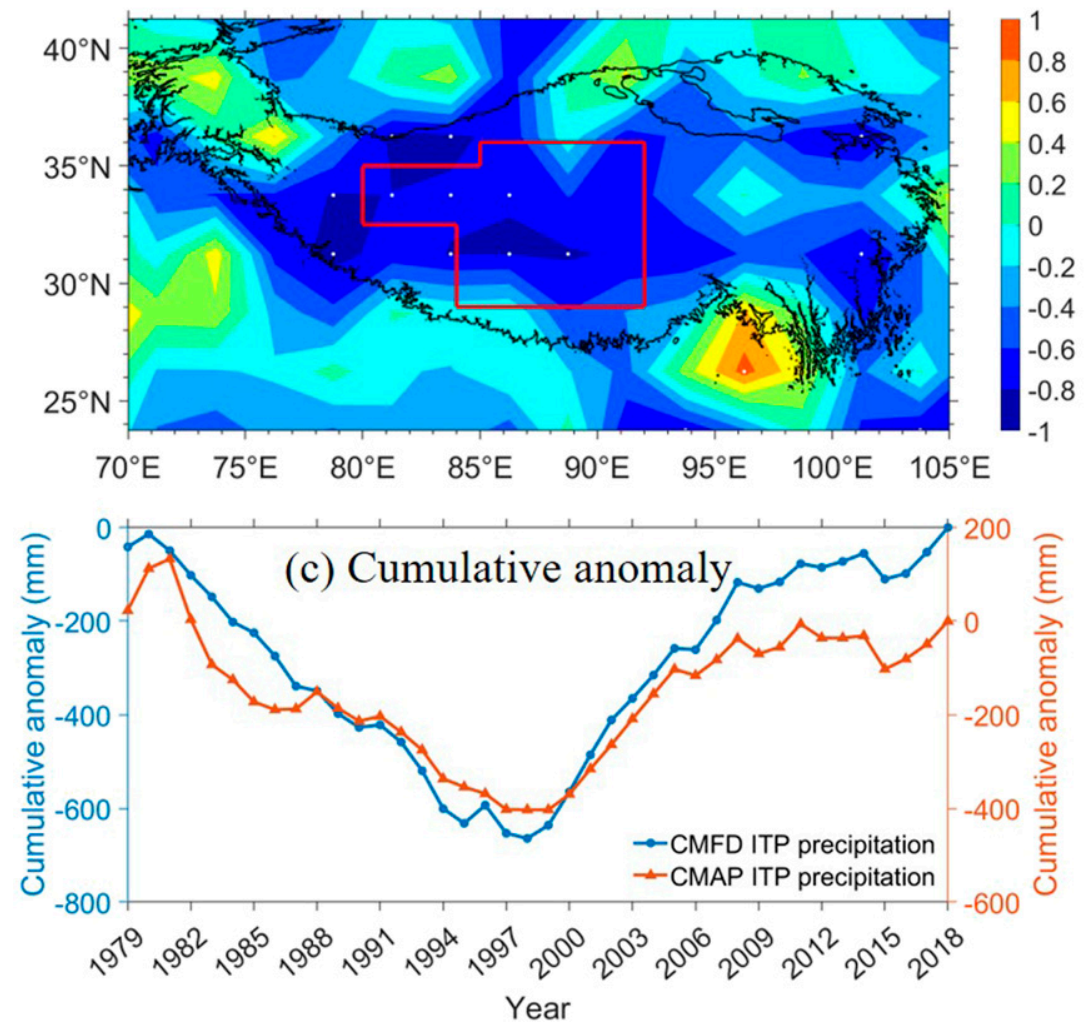

FIG. 7. Correlation between summer TP-averaged 500-hPa zonal wind speed and gridded precipitation from the (a) CMFD and (b) CMAP datasets on interdecadal time scales during 1979-2018. The dotted areas indicate correlation coefficients that are significant at the 0.05 level. The area enclosed by the red solid line is used in this study. The black line denotes the 3000-m contour line of the TP. (c) Cumulative anomalies of the ITP-averaged precipitation from the CMFD and CMAP datasets in summer during 1979-2018.

and that the regionalization of summer precipitation changes in the ITP is reasonable. Furthermore, Figs. $8 \mathrm{c}$ and $8 \mathrm{~d}$ show that interdecadal correlation coefficients between the summer ITP-averaged precipitation and AMO index are 0.89 and 0.82 for the CMFD and CMAP data, respectively; these are comparable to that for the ERA-Interim data shown in Fig. 6b, indicating that our conclusion is not sensitive to the selection of precipitation data sources on the regional scale.

\section{b. Physical picture of the AMO-westerly jet stream-ITP precipitation cascade}

We have demonstrated that the AMO is correlated with the jet stream, and the latter's variability causes 
(a) AMO vs CMFD precipitation

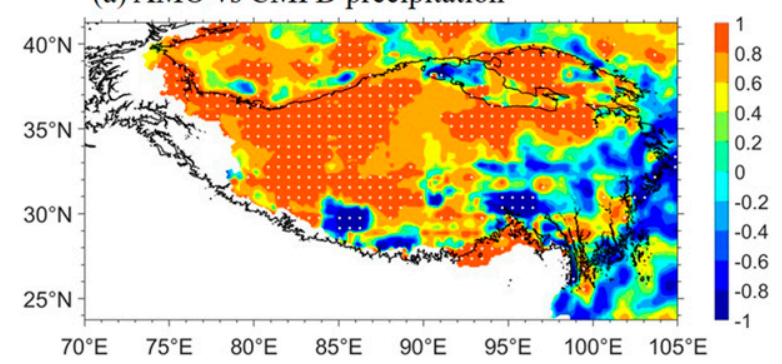

(b) AMO vs CMAP precipitation

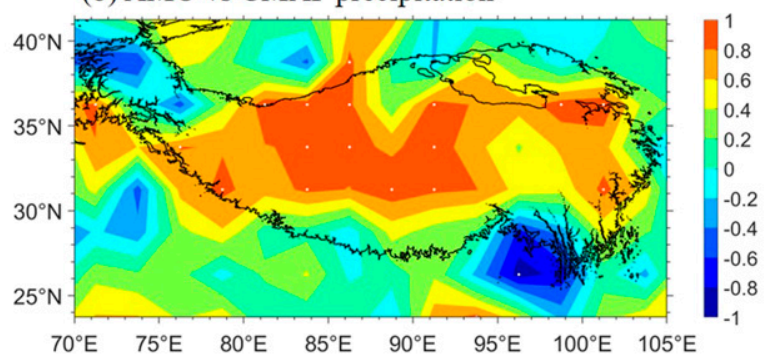

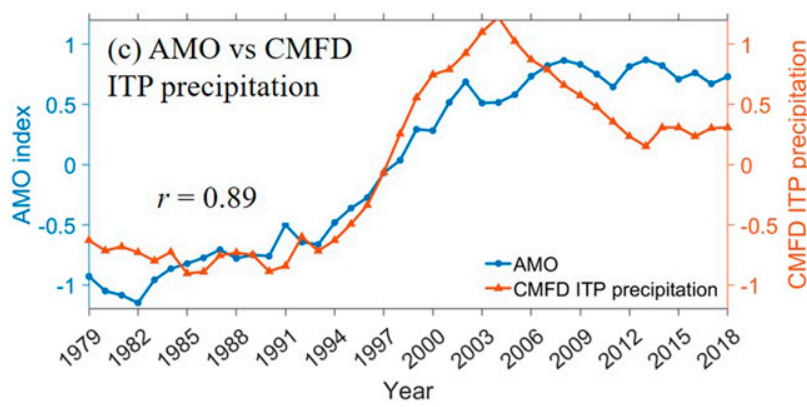

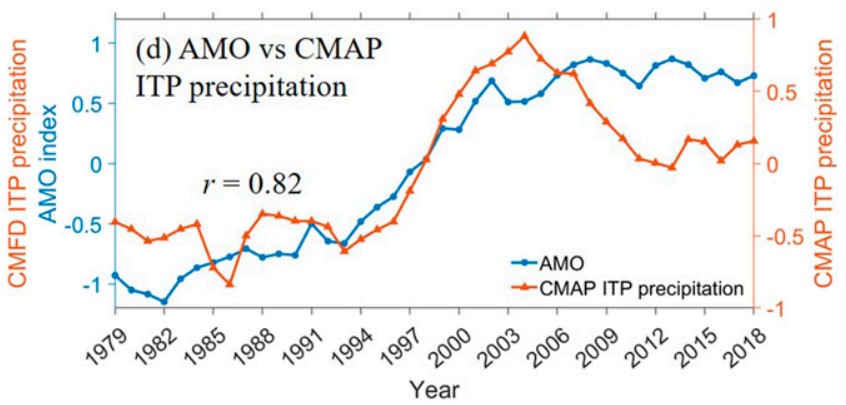

FIG. 8. Correlation of the summer AMO index and gridded precipitation from the (a) CMFD and (b) CMAP datasets on interdecadal time scales. The black line denotes the 3000-m contour line of the TP. The dotted areas indicate correlation coefficients that are significant at the 0.05 level. Also shown are interdecadal variations of the summer AMO index and ITP-averaged precipitation from the (c) CMFD and (d) CMAP datasets; $r$ is the correlation coefficient between the two series. All of the time series are standardized before extracting their interdecadal variations.

a dry or wet condition in the ITP. The following provides a preliminary physical picture on how the AMO affects the jet stream and ITP precipitation variability.

The AMO may play an important role in regulating the "Silk Road Pattern" (SRP) on the decadal time scale (Hong et al. 2017). The SRP is a strong summer teleconnection pattern of cyclonic and anticyclonic anomalies in the upper troposphere along the subtropical westerly jet stream over Eurasia. Previous studies (Hong and $\mathrm{Lu}$ 2016; Hong et al. 2018) have found that the meridional displacement of the jet stream is strongly related to the SRP. Thus, the AMO-SRP-westerly jet stream relationship is worthy of further analysis. Figure 9a shows significant SST warming over the mid- to highlatitude North Atlantic (especially around Greenland) in the positive phase of the AMO. A number of previous studies have focused on tropical Atlantic atmosphereocean interactions, but it is less understood how the atmosphere responds to mid- to high-latitude Atlantic SST anomalies (Kushnir et al. 2002; Kwon et al. 2010; Czaja et al. 2019). As can be seen in Fig. 9b, the AMO warm phase induces a series of high pressure (anticyclone) and low pressure (cyclone) systems over Eurasia at $200 \mathrm{hPa}$, similar to the SRP shown in L. Wang et al. (2017) (their Fig. 1a). This result is also consistent with Hong et al. (2017), who indicated the AMO can modulate the SRP. The anticyclonic anomalies over the Greenland and Baffin
Island correspond well to positive SST anomalies around Greenland, suggesting atmospheric response to diabatic heating generated by local SST anomalies (Kwon et al. 2010; Czaja et al. 2019). These weak cyclonic anomalies to the west of about $80^{\circ} \mathrm{E}$ and strong anticyclonic anomalies to its east lead to the meander of the westerly jet stream. Figure 9c displays the pattern in $500-\mathrm{hPa}$ geopotential height anomalies between the warm and cold phases of the AMO. The similar patterns between Figs. $9 \mathrm{~b}$ and $9 \mathrm{c}$ indicate these anomalies feature a barotropic wave train, which could be forced by North Atlantic SST anomalies (Zhou et al. 2019; Kushnir et al. 2002). These anomalies in SST and geopotential height are also similar to those of Zhou et al. (2019), which demonstrated the impact of summer SST in the northwestern Atlantic on the atmospheric teleconnection pattern from both observation and climate model.

Zhou et al. (2019) found that $67^{\circ}-39^{\circ} \mathrm{W}, 40^{\circ}-55^{\circ} \mathrm{N}$ is the key region over which the northern Atlantic SST can influence the TP water vapor, but in this study, Fig. 9a shows that the key region of Atlantic SST that influences the ITP precipitation is larger than the region they selected. The region enclosed by blue solid lines in Fig. 9a was selected to calculate the key region area-averaged SST. Figure 9d displays correlation between the SST averaged over the key region and $200-\mathrm{hPa}$ geopotential height in summer on interdecadal time scales. The correlation coefficient over Greenland and Baffin Island as 
(a) SST

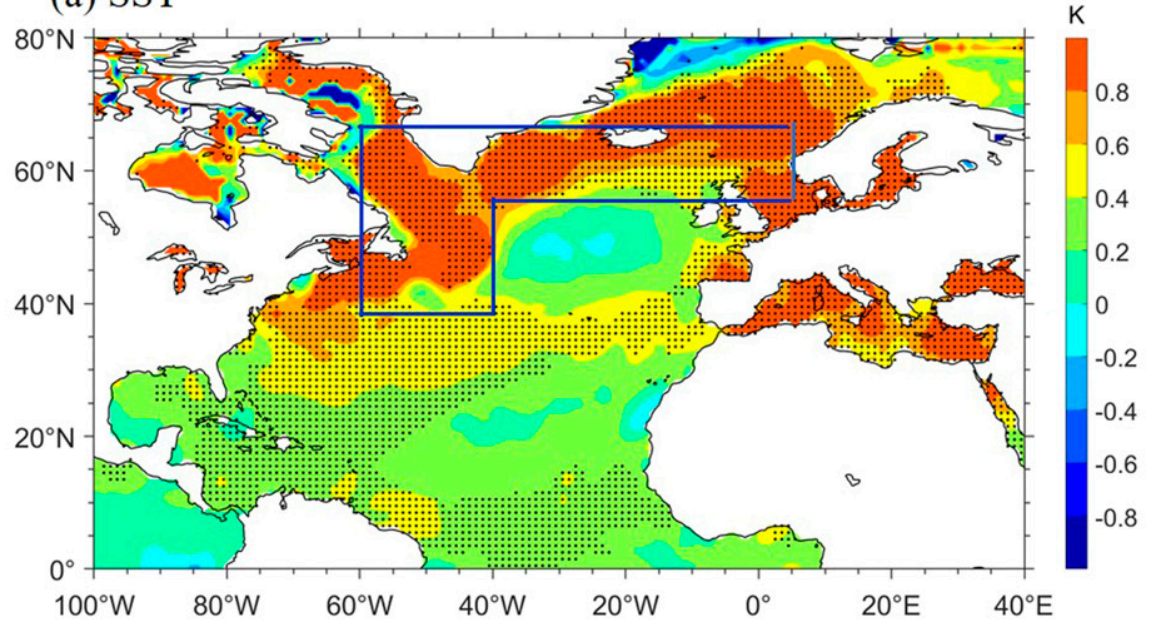

(b) 200hPa: geopotential height

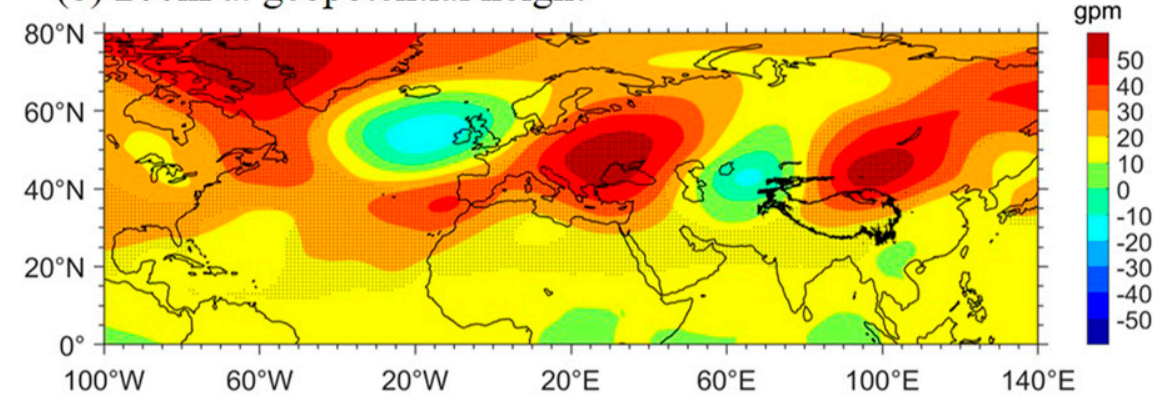

(c) $500 \mathrm{hPa}$ : geopotential height

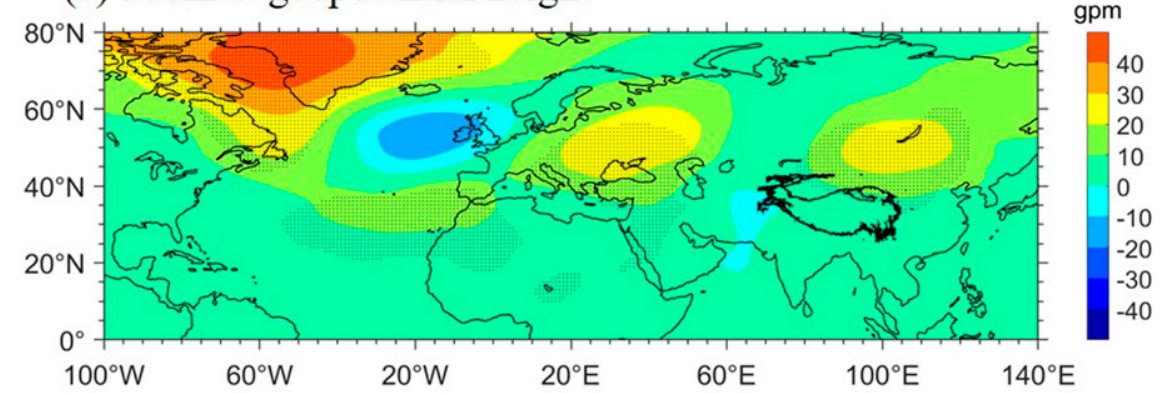

(d) Area-averaged SST vs Gridded geopotential height at $200 \mathrm{hPa}$

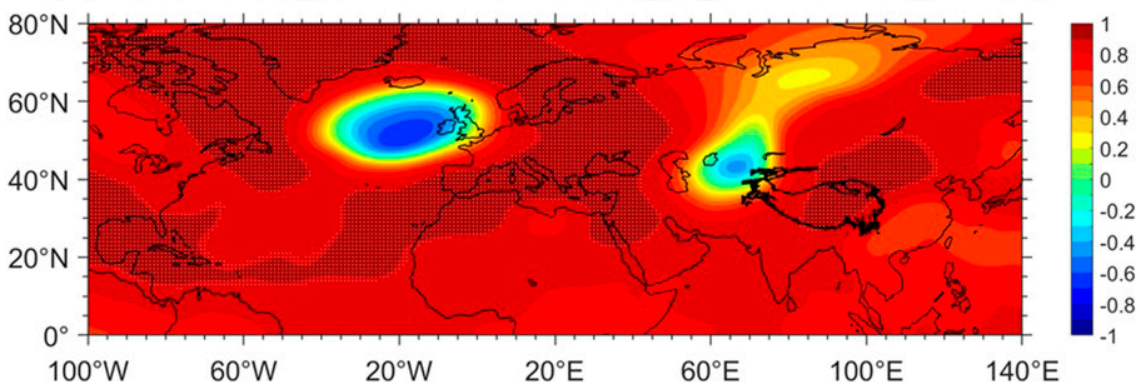

FIG. 9. Differences in summer (a) SST and geopotential height at (b) 200 and (c) $500 \mathrm{hPa}$ between the warm (1998-2018) and cold (1979-97) phases of the AMO (the former minus the latter). (d) Correlation between the SST averaged over the region enclosed by the blue solid line in (a) and 200-hPa geopotential height in summer on interdecadal time scales during 1979-2018. The dotted areas indicate differences or correlation coefficients that are significant at the 0.01 level. 
(a) AMO vs $200 \mathrm{hPa}$ zonal wind (NCEP/NCAR; 1948-2018)

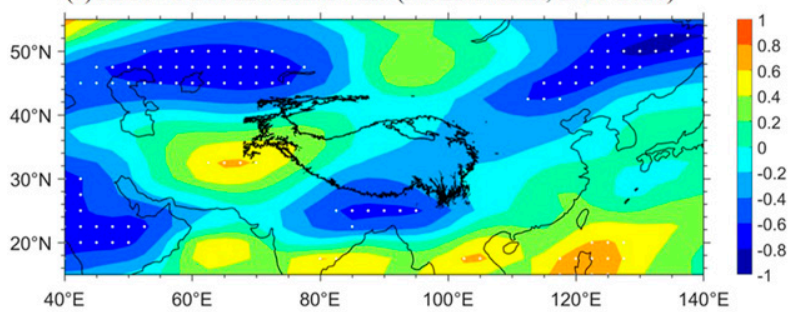

(c) 200hPa: geopotential height (NCEP/NCAR)

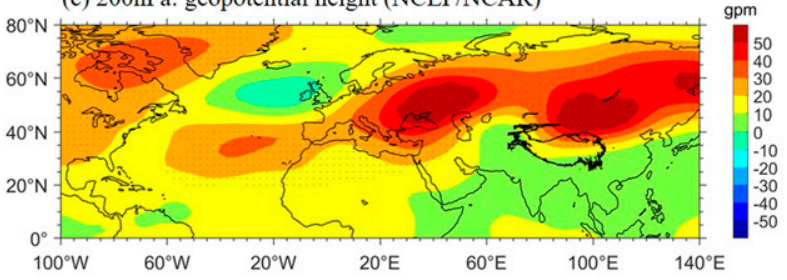

(e) 500hPa: geopotential height (NCEP/NCAR)

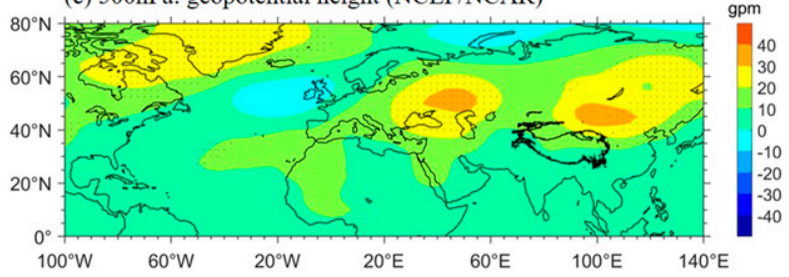

(b) AMO vs $200 \mathrm{hPa}$ zonal wind (JRA-55; 1958-2013)

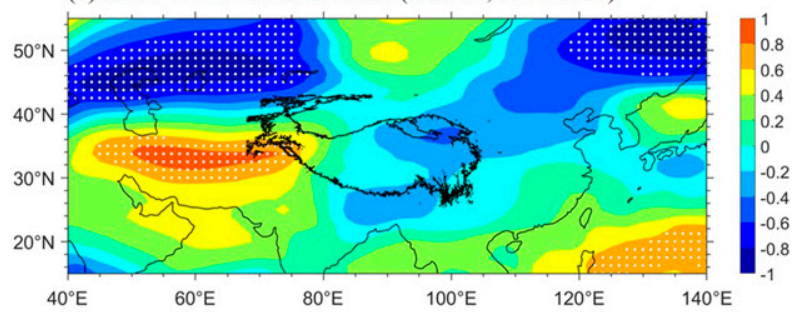

(d) $200 \mathrm{hPa}$ geopotential height (JRA-55)

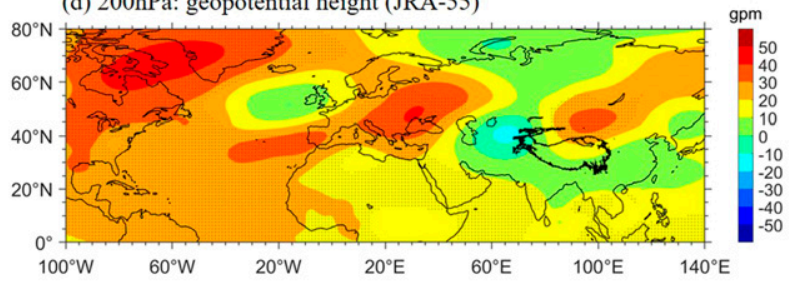

(f) 500hPa: geopotential height (JRA-55)

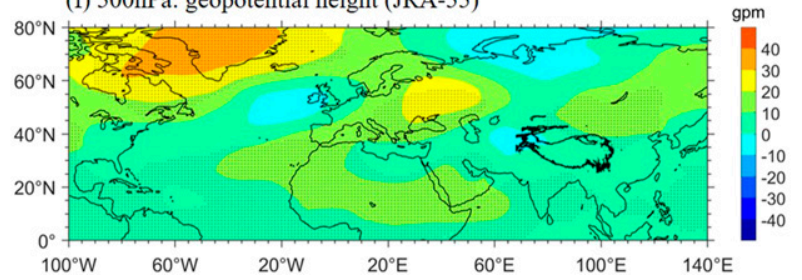

FIG. 10. Correlation between summer AMO index and gridded 200-hPa zonal wind using (a) NCEP-NCAR and (b) JRA-55 data on interdecadal time scales. The dotted areas indicate correlation coefficients that are significant at the 0.1 level. Also shown for (left) NCEPNCAR and (right) JRA-55 are differences in summer geopotential height at (c),(d) 200 and (e),(f) 500 hPa between the positive [1948-57 and 1995-2018 for (c) and (d); 1995-2013 for (e) and (f)] and negative [1958-94 for (c)-(f)] phases of the AMO (the former minus the latter). The dotted areas indicate differences that are significant at the 0.01 level.

well as regions to the east of the ITP is more than 0.90 , corresponding to the anticyclonic anomalies over those regions when the AMO is in the positive phase. These results suggest that SST anomalies over the mid- to highlatitude North Atlantic can affect atmospheric circulations over East Asia through a wave train of barotropic anomalies, but the physical mechanism of the atmosphereocean interactions still needs further study.

Since a cycle of the AMO is about $65-80$ years, we used NCEP-NCAR (1948-2018) and JRA-55 (19582013) reanalysis datasets to test the relationships between the AMO and subtropical jet stream as well as geopotential height. The correlation between the AMO and zonal wind at $200 \mathrm{hPa}$ using the two longer reanalysis datasets on interdecadal time scales shows that the positive phase of the AMO is related to the northward shift of the jet stream near the TP and the southward shift of the jet stream located to the west of the ITP (Figs. 10a,b), which is consistent with what we found using the ERA-Interim reanalysis data. The positive anomalies in zonal wind to the north of the TP in Figs. 10a and 10b are not as obvious as the results derived from the ERA-Interim data, which is mainly due to uncertainties of the two longer reanalysis datasets before 1979. As shown in Figs. 10c-f, the patterns of differences in summer geopotential height using the two longer datasets between the positive and negative phases of the AMO are also similar to those shown in Figs. $9 \mathrm{~b}$ and $9 \mathrm{c}$, indicating the effect of the AMO on geopotential height is robust. Therefore, these results demonstrate that the relationship between the AMO and subtropical jet remains robust for a longer period.

All these processes are summarized in Fig. 11. First, the AMO warm phase induces a wave train of cyclonic and anticyclonic anomalies in summer over Eurasia, causing the westerly jet stream near the TP to weaken and/or shift northward. Then, the westerlies over the TP become weakened, but the westerlies to the east of the ITP are weakened much more than those to its west, causing enhanced air convergence over the ITP. At the same time, due to the enhanced southwest winds to the south of the ITP and convection over the Indian subcontinent, both of which are attributed to the cyclonic anomalies to the west of the ITP, more water vapor intrudes from the Arabian Sea into the ITP. The abovementioned two favorable conditions enhance water vapor convergence over the ITP, causing more precipitation in summer. 

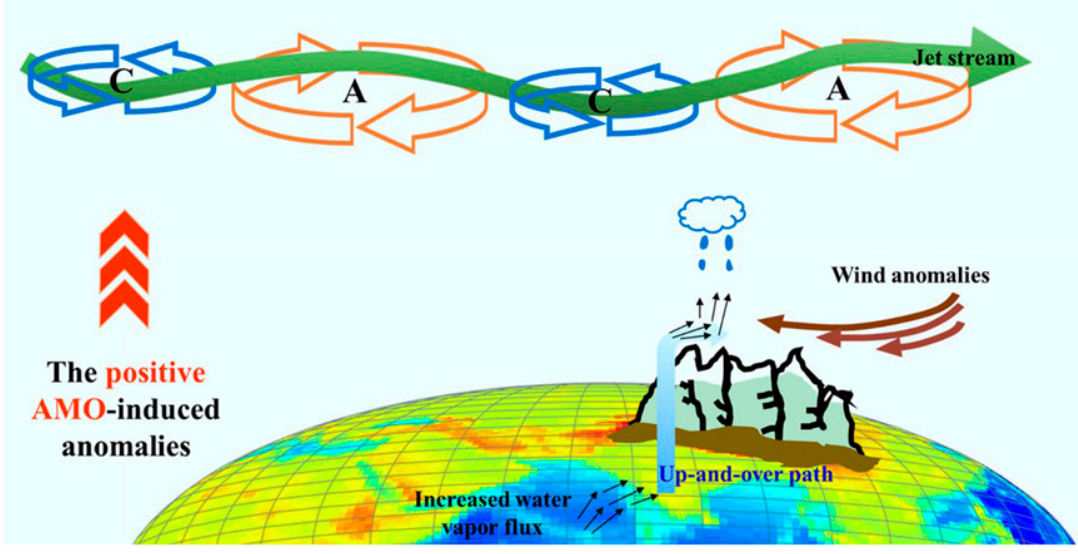

FIG. 11. Schematic diagram of the influence of the AMO on the interdecadal variability in summer precipitation over the ITP. The orange ringed arrows labeled A denote the positive AMO-induced anomalous anticyclone in the upper troposphere. The blue ringed arrows labeled $\mathrm{C}$ denote the positive AMO-induced anomalous cyclone in the upper troposphere. The solid green arrow denotes the subtropical westerly jet stream with a northward shift and weakened strength near the TP. The thin black arrows denote the increased water vapor flux from the Arabian Sea. The thick light-blue arrows denote the "up-and-over" path of water vapor (Dong et al. 2016) resulting from enhanced convection over the Indian subcontinent. The thick brown arrows denote the northeast wind anomalies. The cloud with raindrops indicates increased summer precipitation over the ITP. The mountains denote the TP.

\section{Summary}

The influences of interdecadal variations of atmospheric circulations on summer precipitation over the ITP were analyzed for the years 1979-2018. During the second half of this period, the ITP experienced an increase in precipitation, which caused rapid lake expansion in this region and is of wide concern to both local residents and the research community.

Using the ERA-Interim reanalysis data, we found that the effect of TP-averaged zonal winds on summer precipitation was spatially consistent in the ITP; therefore, this region can be considered as a whole from the perspective of climate changes and lake expansion. The interdecadal change in ITP precipitation (dry before 1997 and wet since 1997) is strongly negatively correlated with the TPaveraged zonal wind at $500 \mathrm{hPa}$. The latter is further determined by both the north-south shift of the subtropical westerly jet stream near the TP and its strength. The meridional position of the jet stream is positively correlated with the ITP precipitation on interdecadal time scales $(r=$ 0.69 ), and the jet stream strength is negatively correlated with the ITP precipitation $(r=-0.92)$. Either the northward shift or the weakening of the jet stream could lead to an increase in summer precipitation over the ITP, where most of the lakes have rapidly expanded since the mid1990s. Therefore, the interdecadal variations in summer precipitation over the ITP are the result of the joint influence of jet stream position and strength.
We further found that the AMO was a key factor influencing summer precipitation over the ITP on interdecadal time scales. Combined with the anomalous atmospheric circulations linked to interdecadal variations in precipitation, a possible mechanism affecting the precipitation has been proposed. Since the mid-1990s, the AMO has been in its warm phase and has induced a wave train of cyclonic and anticyclonic anomalies in summer, enhancing the meandering of the westerly jet. These anticyclonic anomalies to the east of the ITP cause a northward shift and/or weakening of the jet stream near the TP. The northward shift or weakening of the jet stream causes weakened westerly winds over the TP downward, which weakens water vapor transport beyond eastern TP boundary and facilitates the convergence of water vapor over the ITP. At the same time, the anomalous cyclone to the west of the ITP enhances southeast winds and convection over the India subcontinent, thus promoting water vapor transport from the Arabian Sea. The favorable wind field and moisture conditions eventually result in increased summer precipitation over the ITP.

Therefore, the AMO could be used as one of the predictive factors for summer precipitation over the ITP on interdecadal time scales, which may support local hydrological and ecological policy decision-making.

Acknowledgments. The authors sincerely thank Editor Dr. Hisashi Nakamura and the three anonymous reviewers 
for their constructive comments, which were very helpful for improving the quality of this work. This work was jointly supported by the Strategic Priority Research Program of Chinese Academy of Sciences (Grant XDA2006010201) and National Science Foundation of China (Grants 91537210 and 41975125). The CMA station data were obtained from the National Meteorological Information Center (http://data.cma.cn/). The Dataset of river basins map over the TP (2016) was provided by the National Tibetan Plateau Data Center (http://data.tpdc.ac.cn/). The CMFD dataset was developed by the Data Assimilation and Modeling Center for Tibetan Multi-spheres, Institute of Tibetan Plateau Research, Chinese Academy of Sciences. The ERA-Interim reanalysis data were provided by ECMWF (https://apps.ecmwf.int/datasets/). The CMAP precipitation data and the AMO index were provided by the NOAA/OAR/ESRL PSD (https:// www.esrl.noaa.gov/psd/). Special thanks are given to Drs. Guoqing Zhang and Yanbin Lei for providing the lake data.

\section{REFERENCES}

Berrisford, P., P. Kållberg, S. Kobayashi, D. Dee, S. Uppala, A. J. Simmons, P. Poli, and H. Sato, 2011: Atmospheric conservation properties in ERA-Interim. Quart. J. Roy. Meteor. Soc., 137, 1381-1399, https://doi.org/10.1002/qj.864.

Bibi, S., L. Wang, X. P. Li, J. Zhou, D. L. Chen, and T. D. Yao, 2018: Climatic and associated cryospheric, biospheric, and hydrological changes on the Tibetan Plateau: A review. Int. J. Climatol., 38, e1-e17, https://doi.org/10.1002/joc.5411.

Curio, J., and D. Scherer, 2016: Seasonality and spatial variability of dynamic precipitation controls on the Tibetan Plateau. Earth Syst. Dyn., 7, 767-782, https://doi.org/10.5194/esd-7-7672016.

Czaja, A., C. Frankignoul, S. Minobe, and B. Vannière, 2019: Simulating the midlatitude atmospheric circulation: What might we gain from high-resolution modeling of air-sea interactions? Curr. Climate Change Rep., 5, 390-406, https:// doi.org/10.1007/s40641-019-00148-5.

Dee, D. P., and Coauthors, 2011: The ERA-Interim reanalysis: Configuration and performance of the data assimilation system. Quart. J. Roy. Meteor. Soc., 137, 553-597, https://doi.org/ 10.1002/qj.828.

Dong, W. H., and Coauthors, 2016: Summer rainfall over the southwestern Tibetan Plateau controlled by deep convection over the Indian subcontinent. Nat. Commun., 7, 10925, https:// doi.org/10.1038/ncomms10925.

Enfield, D. B., A. M. Mestas-Nuñez, and P. J. Trimble, 2001: The Atlantic multidecadal oscillation and its relation to rainfall and river flows in the continental U.S. Geophys. Res. Lett., 28 , 2077-2080, https://doi.org/10.1029/2000GL012745.

He, J., and K. Yang, 2011: China Meteorological Forcing Dataset. Cold and Arid Regions Science Data Center, accessed 19 March 2019, https://doi.org/10.3972/westdc.002.2014.db.

, - _ W. Wang, H. Lu, J. Qin, Y. Chen, and X. Li, 2020: The first high-resolution meteorological forcing dataset for land process studies over China. Sci. Data, 7, 25, https://doi.org/ 10.1038/s41597-020-0369-y.
Hong, X. W., and R. Y. Lu, 2016: The meridional displacement of the summer Asian jet, Silk Road Pattern, and tropical SST anomalies. J. Climate, 29, 3753-3766, https://doi.org/10.1175/ JCLI-D-15-0541.1.

, _ _ , and S. L. Li, 2017: Amplified summer warming in Europe-West Asia and Northeast Asia after the mid-1990s. Environ. Res. Lett., 12, 094007, https://doi.org/10.1088/17489326/aa7909.

,$- \ldots$, and — 2018: Asymmetric relationship between the meridional displacement of the Asian westerly jet and the Silk Road Pattern. Adv. Atmos. Sci., 35, 389-396, https://doi.org/ 10.1007/s00376-017-6320-2.

Immerzeel, W. W., L. P. H. van Beek, and M. F. P. Bierkens, 2010: Climate change will affect the Asian water towers. Science, 328, 1382-1385, https://doi.org/10.1126/science.1183188.

Kalnay, E., and Coauthors, 1996: The NCEP/NCAR 40-Year Reanalysis Project. Bull. Amer. Meteor. Soc., 77, 437-471, https://doi.org/10.1175/1520-0477(1996)077<0437:TNYRP> 2.0.CO;2.

Kerr, R. A., 2000: A North Atlantic climate pacemaker for the centuries. Science, 288, 1984-1985, https://doi.org/10.1126/ science.288.5473.1984.

Kitoh, A., and O. Arakawa, 2016: Reduction in the east-west contrast in water budget over the Tibetan Plateau under a future climate. Hydrol. Res. Lett., 10, 113-118, https://doi.org/ 10.3178/hrl.10.113.

Kobayashi, S., and Coauthors, 2015: The JRA-55 reanalysis: General specifications and basic characteristics. J. Meteor. Soc. Japan, 93, 5-48, https://doi.org/10.2151/jmsj.2015-001.

Kuang, X. Y., and Y. C. Zhang, 2006: Impact of the position abnormalities of East Asian subtropical westerly jet on summer precipitation in middle-lower reaches of Yangtze River. Plateau Meteor., 25, 382-389.

Kushnir, Y., W. A. Robinson, I. Bladé, N. M. J. Hall, S. Peng, and R. Sutton, 2002: Atmospheric GCM response to extratropical SST anomalies: Synthesis and evaluation. J. Climate, 15, 2233-2256, https://doi.org/10.1175/1520-0442(2002)015<2233: AGRTES>2.0.CO;2.

Kwon, Y.-O., M. A. Alexander, N. A. Bond, C. Frankignoul, H. Nakamura, B. Qiu, and L. Thompson, 2010: Role of the Gulf Stream and Kuroshio-Oyashio system in large-scale atmosphere-ocean interaction: A review. J. Climate, 23, 3249-3281, https://doi.org/10.1175/2010JCLI3343.1.

Lei, Y. B., T. D. Yao, B. W. Bird, K. Yang, J. Q. Zhai, and Y. W. Sheng, 2013: Coherent lake growth on the central Tibetan Plateau since the 1970s: Characterization and attribution. J. Hydrol., 483, 61-67, https://doi.org/10.1016/j.jhydrol.2013.01.003.

, K. Yang, B. Wang, Y. W. Sheng, B. W. Bird, G. Q. Zhang, and L. Tian, 2014: Response of inland lake dynamics over the Tibetan Plateau to climate change. Climatic Change, 125, 281290, https://doi.org/10.1007/s10584-014-1175-3.

_, Y. L. Zhu, B. Wang, T. D. Yao, K. Yang, X. W. Zhang, J. Q. Zhai, and N. Ma, 2019: Extreme lake level changes on the Tibetan Plateau associated with the 2015/2016 El Niño. Geophys. Res. Lett., 46, 5889-5898, https://doi.org/10.1029/ 2019GL081946.

Liang, X. Z., and W. C. Wang, 1998: Associations between China monsoon rainfall and tropospheric jets. Quart. J. Roy. Meteor. Soc., 124, 2597-2623, https://doi.org/10.1002/qj.49712455204.

Lin, C. G., K. Yang, J. Qin, and R. Fu, 2013: Observed coherent trends of surface and upper-air wind speed over China since 1960. J. Climate, 26, 2891-2903, https://doi.org/10.1175/JCLID-12-00093.1. 
Lin, Z. D., and R. Y. Lu, 2005: Interannual meridional displacement of the East Asian upper-tropospheric jet stream in summer. $A d v$. Atmos. Sci., 22, 199-211, https://doi.org/10.1007/BF02918509.

Liu, T., K. Yang, J. Qin, and F. Q. Tian, 2018: Construction and applications of time series of monthly precipitation at weather stations in the central and eastern Qinghai-Tibetan Plateau. Plateau Meteor., 37, 1449-1457.

Qiao, B. J., L. P. Zhu, and R. M. Yang, 2019: Temporal-spatial differences in lake water storage changes and their links to climate change throughout the Tibetan Plateau. Remote Sens. Environ., 222, 232-243, https://doi.org/10.1016/j.rse.2018.12.037.

Qiu, J., 2008: China: The third pole. Nature, 454, 393-396, https:// doi.org/10.1038/454393A.

Rayner, N. A., D. E. Parker, E. B. Horton, C. K. Folland, L. V. Alexander, D. P. Rowell, E. C. Kent, and A. Kaplan, 2003: Global analyses of sea surface temperature, sea ice, and night marine air temperature since the late nineteenth century. J. Geophys. Res., 108, 4407, https://doi.org/10.1029/2002JD002670.

Sampe, T., and S. P. Xie, 2010: Large-scale dynamics of the meiyubaiu rainband: Environmental forcing by the westerly jet. J. Climate, 23, 113-134, https://doi.org/10.1175/2009JCLI3128.1.

Shen, Y., and A. Y. Xiong, 2016: Validation and comparison of a new gauge-based precipitation analysis over mainland China. Int. J. Climatol., 36, 252-265, https://doi.org/10.1002/joc.4341.

Si, D., and Y. H. Ding, 2016: Oceanic forcings of the interdecadal variability in East Asian summer rainfall. J. Climate, 29, 76337649, https://doi.org/10.1175/JCLI-D-15-0792.1.

Ueda, H., H. Kamahori, and N. Yamazaki, 2003: Seasonal contrasting features of heat and moisture budgets between the eastern and western Tibetan Plateau during the GAME IOP. J. Climate, 16, 2309-2324, https://doi.org/10.1175/2757.1.

Wang, L., P. Xu, W. Chen, and Y. Liu, 2017: Interdecadal variations of the Silk Road pattern. J. Climate, 30, 9915-9932, https://doi.org/10.1175/JCLI-D-17-0340.1.

Wang, Y. M., S. L. Li, and D. H. Luo, 2009: Seasonal response of Asian monsoonal climate to the Atlantic Multidecadal Oscillation. J. Geophys. Res., 114, D02112, https://doi.org/ 10.1029/2008JD010929.

Wang, Z. Q., A. M. Duan, S. Yang, and K. Ullah, 2017: Atmospheric moisture budget and its regulation on the variability of summer precipitation over the Tibetan Plateau. J. Geophys. Res., 122, 614-630, https://doi.org/10.1002/2016JD025515.

Xie, P., and P. A. Arkin, 1997: Global precipitation: A 17-year monthly analysis based on gauge observations, satellite estimates, and numerical model outputs. Bull. Amer. Meteor. Soc., 78, 2539-2558, https://doi.org/10.1175/1520-0477(1997)078<2539: GPAYMA $>2.0 . \mathrm{CO} ; 2$.

Xie, Z., Y. Du, and S. Yang, 2015: Zonal extension and retraction of the subtropical westerly jet stream and evolution of precipitation over East Asia and the western Pacific. J. Climate, 28, 6783-6798, https://doi.org/10.1175/JCLI-D-14-00649.1.

Xu, X. D., C. G. Lu, X. H. Shi, and S. T. Gao, 2008: World water tower: An atmospheric perspective. Geophys. Res. Lett., 35, L20815, https://doi.org/10.1029/2008GL035867.

Yang, K., B. S. Ye, D. G. Zhou, B. Y. Wu, T. Foken, J. Qin, and Z. Y. Zhou, 2011: Response of hydrological cycle to recent climate changes in the Tibetan Plateau. Climatic Change, 109, 517-534, https://doi.org/10.1007/s10584-011-0099-4.
- , H. Wu, J. Qin, C. G. Lin, W. J. Tang, and Y. Y. Chen, 2014: Recent climate changes over the Tibetan Plateau and their impacts on energy and water cycle: A review. Global Planet. Change, 112, 79-91, https://doi.org/10.1016/j.gloplacha.2013.12.001.

, H. Lu, S. Y. Yue, G. Q. Zhang, Y. B. Lei, Z. La, and W. Wang, 2018: Quantifying recent precipitation change and predicting lake expansion in the inner Tibetan Plateau. Climatic Change, 147, 149-163, https://doi.org/ 10.1007/s10584-017-2127-5.

Yang, L. M., and Q. Y. Zhang, 2008: Climate features of summer Asia subtropical westerly jet stream. Climate Environ. Res., 13, 10-20.

Yang, S., K.-M. Lau, and K.-M. Kim, 2002: Variations of the East Asian jet stream and Asian-Pacific-American winter climate anomalies. J. Climate, 15, 306-325, https://doi.org/10.1175/ 1520-0442(2002)015<0306:VOTEAJ > 2.0.CO;2.

Yao, T. D., and Coauthors, 2012: Different glacier status with atmospheric circulations in Tibetan Plateau and surroundings. Nat. Climate Change, 2, 663-667, https://doi.org/10.1038/ nclimate1580.

Zhang, G. Q., 2019: Dataset of river basins map over the TP (2016). National Tibetan Plateau Data Center, accessed 1 January 2020, https://doi.org/10.11888/BaseGeography.tpe.249465.file.

—, T. D. Yao, H. J. Xie, S. C. Kang, and Y. B. Lei, 2013: Increased mass over the Tibetan Plateau: From lakes or glaciers? Geophys. Res. Lett., 40, 2125-2130, https://doi.org/ 10.1002/grl.50462.

_ alpine lake changes on Asia's high plateaus during the past four decades. Geophys. Res. Lett., 44, 252-260, https://doi.org/ 10.1002/2016GL072033.

_ , and Coauthors, 2017b: Lake volume and groundwater storage variations in Tibetan Plateau's endorheic basin. Geophys. Res. Lett., 44, 5550-5560, https://doi.org/10.1002/2017GL073773.

_ across China during 1960s-2015 and its natural and anthropogenic causes. Remote Sens. Environ., 221, 386-404, https:// doi.org/10.1016/j.rse.2018.11.038.

- W. Luo, W. Chen, and G. Zheng, 2019b: A robust but variable lake expansion on the Tibetan Plateau. Sci. Bull., 64, 1306-1309, https://doi.org/10.1016/j.scib.2019.07.018.

Zhao, Y., M. Z. Wang, A. N. Huang, H. J. Li, W. Huo, and Q. Yang, 2014: Relationships between the West Asian subtropical westerly jet and summer precipitation in northern Xinjiang. Theor. Appl. Climatol., 116, 403-411, https://doi.org/10.1007/ s00704-013-0948-3.

— X. J. Yu, J. Q. Yao, and X. N. Dong, 2018: Evaluation of the subtropical westerly jet and its effects on the projected summer rainfall over central Asia using multi-CMIP5 models. Int. J. Climatol., 38, e1176-e1189, https://doi.org/10.1002/joc.5443

Zhou, C. Y., P. Zhao, and J. M. Chen, 2019: The interdecadal change of summer water vapor over the Tibetan Plateau and associated mechanisms. J. Climate, 32, 4103-4119, https:// doi.org/10.1175/JCLI-D-18-0364.1.

Zwiers, F. W., and H. von Storch, 1995: Taking serial correlation into account in tests of the mean. J. Climate, 8, 336-351, https:// doi.org/10.1175/1520-0442(1995)008<0336:TSCIAI >2.0.CO;2. 